\title{
Conf-930616-34
}

UCRL-JC-112510

PREPRINT

\section{A FET-SWITCHED INDUCTION ACCELERATOR CELL}

\author{
H. C. Kirbie, W. R. Cravey, S. A. Hawkins, M. A. Newton, \\ and C. W. Ollis

\section{Lawrence Livermore National Laboratory, University of Califormia P.O. Box 5508, L-440, Livermore California 94550, USA}

This paper was prepared for submittal to the

Proceedings of the 9th IEEE International Pulsed Power Conference

Albuquerque, NM, USA

June 21-23, 1993

TECEIVL.

June 10, 1993

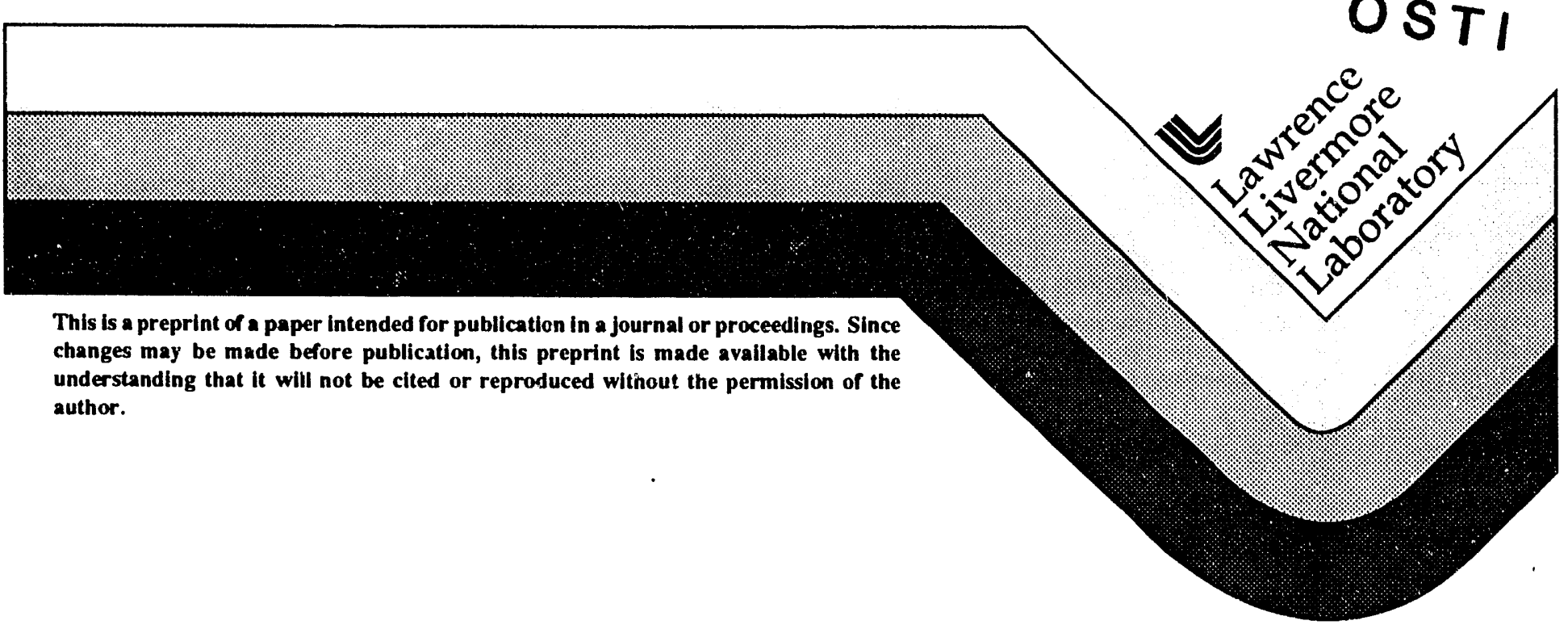




\section{DISCLAIMER}

This document was prepared as an account of work sponsored by an agency of the United States Government. Neither the United States Government nor the University of California nor any of their employees. makes any warranty, express or implied, or assumes any legal liability or responsibility for the accuracy, completeness, or usefulness of any information. apparatus, product, or process disclosed, or represents that its use would not infringe privately owned rights. Reference herein to any specific commercial products. process. or service by trade name. trademark, manufacturer, or otherwise. does not necessarily constitute or imply its endorsement. recommendation. or favoring by the United States Government or the University $n$ California. The views and opinions of authors expressed herein do not necessarily state or reflect those of the United States Government or the University of California, and shall not be used for advertising or product endorsement purposes. 


\title{
A FET-SWITCHED INDUCTION ACCELERATOR CELL*
}

\author{
H. C. Kirbie, W. R. Cravey, S. A. Hawkins, M. A. Newton, and C. W. Ollis \\ Lawrence Livermore National Laboratory
}

P. O. Box 5508

Livermore, CA 94550

\section{Abstract}

An array of 24 field-effect transistors (FETs) is being used to switch a nominal $4-\mathrm{kV}, 1-\mu \mathrm{s}$ pulse onto a Metglas induction core at pulse rates exceeding $100 \mathrm{kHz}$. Each transistor receives isolated gate power from a dc/dc converter and analog pulse control via an optical fiber. The array is part of a specialized circuit architecture that generates bursts of pulses while providing for core reset between pulses. The circuit will accommodate variations in pulse width, repetition frequency (prf), pulse amplitude, burst length and reset interval. The various circuit elements are assembled directly onto the core structure to yield a compact, low-impedance package.

Two prototype machines are presently under development. A 24FET machine is in operation and capable of $4.2-\mathrm{kV}, 1-\mu \mathrm{s}$ pulses (max.) at a 120-kflz prf for short bursts. Pulse rise and fall times are $25 \mathrm{~ns}$ and $65 \mathrm{~ns}$ respectively. A 128-FET machine is under construction which should be capable of $6-\mathrm{kV}, 1-\mu \mathrm{s}$ pulses (max.) at a $150-\mathrm{kHz}$ prf for long bursts.

\section{Introduction}

\section{Heavy-Ion Fusion}

Heavy-ion beams are under study as a future drive source for inertial fusion. In September 1990, a report from the Fusion Policy Advisory Committee (FPAC) endorsed heavy-ion accelerators as the most promising driver for inertial fusion energy [1]. Heavy-ion fusion has been studied in Europe and Japan using of accelerators $[2,3]$, and in the U. S. using linear induction accelerators [4]. The linear induction accelerator approach is presently being pursued by the Lawrence Berkeley Laboratory (LBL) and by the Lawrence Livermore National Laboratory (LLNL).

As with all large-scale inertial fusion technologies, driver cost is an important consideration when selecting a research pathway. In a study coordinated with LBL, researchers at LLNL have examined a more cost-effective use of induction accelerator technology by proposing a circular configuration of accelerator components, known as a recirculator [5]. A recirculating accelerator yields a system-wide cost savings by having the ion bunch gain multiple use from the expensive capital investments in cells, modulators, and beam-focusing elements. However, the recirculation method requires the cell modulators to operate at a $50-$ to $100-\mathrm{kHz}$ prf, due to the short ion transit time around the circle. In addition, the modulators must possess great prf agility to keep pace with the increasing ion speed and great agility in pulse width to match the shrinking bunch length.

\section{LSE Recirculator}

The development of high prf, $100-\mathrm{kV}$ induction cell modulators , for a commercial fusion driver is a formidable task. We hope to gain insight into the problem by first building a small-scale recirculator consisting of many 5-kV induction cells amanged in a 30-m diameter ring. The proposed small-scale recirculator will accept $10-\mathrm{MeV}$ potassium ions $\left(\mathrm{K}^{+}\right)$from a linear accelerator and continue their acceleration to $60-\mathrm{MeV}$ by redirecting the ion bunch around the ring until a final energy is attained. The ions gain speed with each circulation, so the cell prf must also keep pace by increasing from 70 $\mathrm{kHz}$ to $200 \mathrm{kHz}$ over a nominal burst length of 100 pulses. The 10 $\mathrm{MeV}$ linear accelerator, under development at LBL, is called ILSE (Induction Linac Systems Experiment) and is shown in Figure 1 with the proposed recirculator experiment. Table 1 lists a few of the ILSE specifications along with the pulse requirements for an induction recirculator cell.

Our research is focused on the development of an induction cell and modulator combination that meets the ILSE recirculator requirements in Table 1 . Herein, we present data and modeling results from our first device and describe our progress toward a more advanced machine.

\footnotetext{
"Work performed under the auspices of the U. S. Deparment of Energy by the Lawrence Livermore National l.athoratory under W'-7405-IENG-48.
}

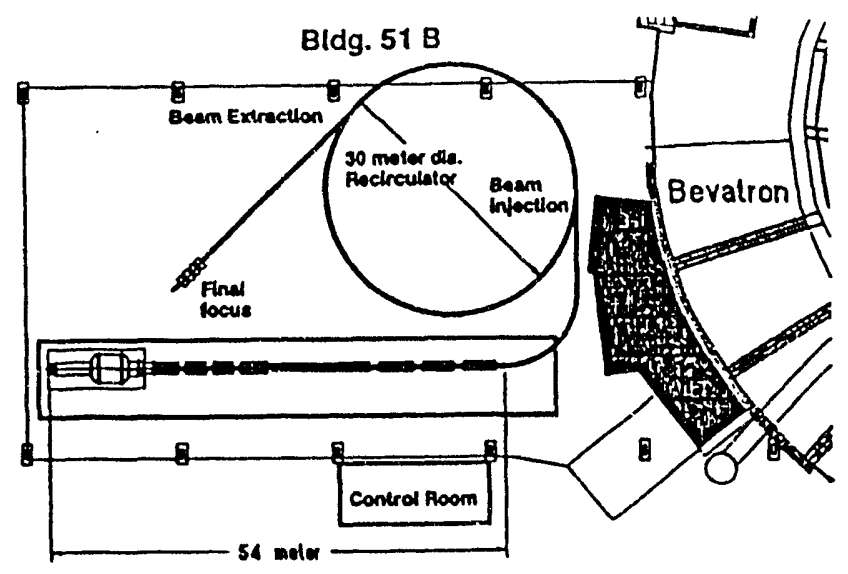

Figure 1. Floor plan of the ILSE accelerator facility showing the recirculator experiment.

\section{Table 1}

\begin{tabular}{|c|c|c|}
\hline Accelerator & ifications & Recirculator Specifications \\
\hline Mass number & 39.1 & Initial kinetic energy $10.5 \mathrm{MeV}$ \\
\hline Charge state & +1 & Final kinetic energy $\quad 60 \mathrm{MeV}$ \\
\hline Initial: & & Pulse duration $\quad 1.0-0.4 \mu \mathrm{s}$ \\
\hline kinetic energy & $2 \mathrm{MeV}$ & Cell voltage \\
\hline $\begin{array}{l}\text { pulse duration } \\
\text { Einal: }\end{array}$ & $1.0 \mu \mathrm{s}$ & Pulse Rep. Rate \\
\hline $\begin{array}{l}\text { kinetic energy } \\
\text { pulse duration } \\
\text { beam energy } \\
\text { Length of Linac }\end{array}$ & $\begin{array}{l}10.5 \mathrm{MeV} \\
0.4 \mu \mathrm{s} \\
33 \mathrm{~J} \\
54 \mathrm{~m}\end{array}$ & Circumference \\
\hline
\end{tabular}

\section{System Issues and Circuit Architecture}

Traditional induction accelerator designs separate the functions of cell and modulator into distinct units and interconnect the two by coaxial cables. In a recirculator application, the high cell impedance due to cable interconnections is undesirable because it can lead to a longitudinal instability in the ion beam [6]. The instability issue and the need for pulse format agility led us to merge the functions of cell and modulator into a single low-impedance device. Cost and system efficiency are also important issues that we explored in a tradeoff between initial core costs and magnetic losses. By selecting a well oversized core, we reduced $\mathrm{dB} / \mathrm{dt}$ and thereby reduced core losses.

We selected the circuit architecture of Figure 2(a) because it generates voltage pulses for acceleration and reset with a single on/off command. When the switch $S_{1}$ is closed, the energy storage capacitor

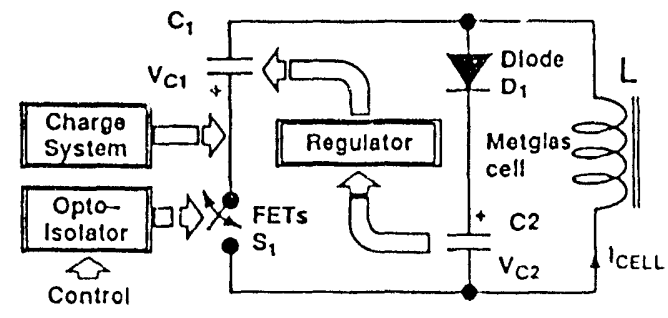

Figure 2(a). Circuit diatgram showing switch $\mathrm{S}_{1}$, energy storage capacitor $\mathrm{C}_{1}$, and reset capacitor $\mathrm{C}_{2}$. The regulator controls the voltage on $\mathrm{C}_{2}$ by returning energy to $\mathrm{C}_{1}$ 


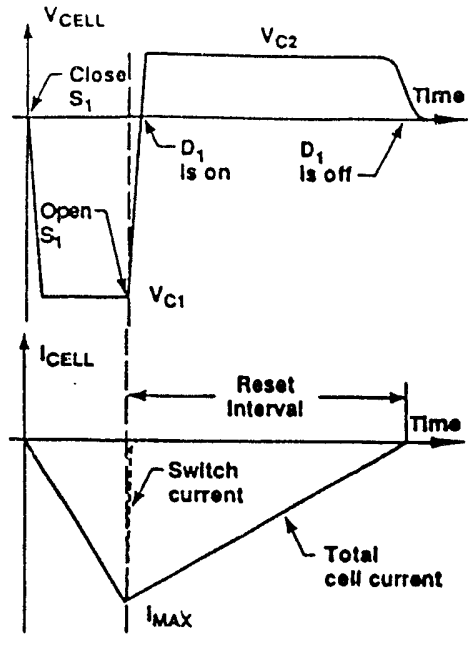

Figure 2(b). Idealized cell voltage and cell current waveforms for the circuit in Figure 2(a).

$\mathrm{C}_{1}$ is connected to the Metglas recirculator cell. Once the acceleration pulse has ended, the switch opens and the cell current is automatically diverted from the switch branch to the reset capacitor $\mathrm{C}_{2}$, as shown in Figure 2(b). The reset capacitor is precharged +o a voltage that dictates the rate of cell current decay and resets the core material by returning the flux density back to its original value. Additional core reset is provided by snubber capacitors across the switch (not shown) and current from the external charging system. The charge system replenishes only a small voltage deficit between pulses because $C_{1}$ contains far more energy than the ion beam and core material consume per pulse. The capacitance of $C_{2}$ is large compared to $C_{1}$ so that the voltage on $C_{2}$ increases only slightly from each pulse. Since system efficiency is a key issue, we propose the use of a regulator element that returns the energy recovered by $\mathrm{C}_{2}$ back to $\mathrm{C}_{1}$ [7].

FETs were selected as the switching element because they have unique properties: fast rise and fall times, low gate-drive power, low on-state impedance, and a capacity for high prf operation. These FET characteristics make series and parallel switch configurations easy to design and very effective in high prf applications [8]. We arranged our FETs into a series-parallel array of independent switching circuits, where each circuit is powered by a dc/dc converter and commanded on and off by a fast optical link. Our earliest switching system consisted of only four circuits (two in series by two in parallel) that switched 1 $\mathrm{kV}$ onto a 2605S-3A Meiglas core [9]. Our latest machine surrounds the same Metglas core with 24 independent switching circuits by stacking six switches in series and connecting four switch stacks in parallel. We call this switching configuration our $6 \times 4$ machine.

\section{$6 \times 4$ Machine Performance}

Figure 3 is a simplified network diagram of the $6 \times 4$ machine showing the four energy storage capacitor banks, four reset circuits, and the four switch branches. The circuit elements in Figure 3 are grouped around the core in four quadrants, as shown in Figure 4.

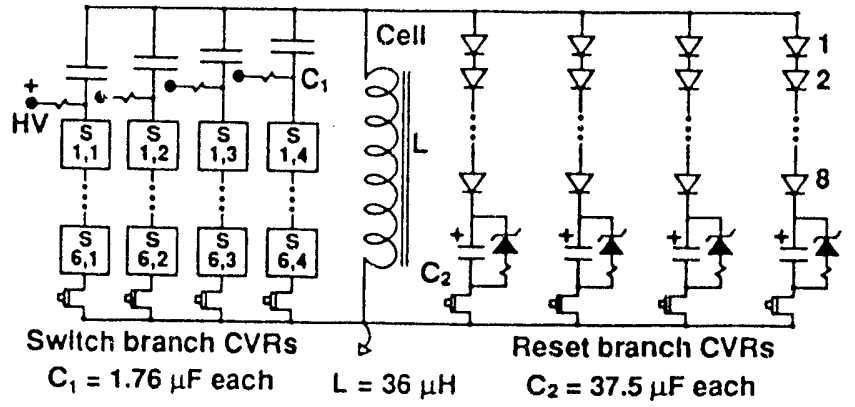

Figure 3. Network diagram for the $6 \times 4$ machine. Each switching element is a circuit card containing a single FET, gate driver, optical receiver, and a power converter.

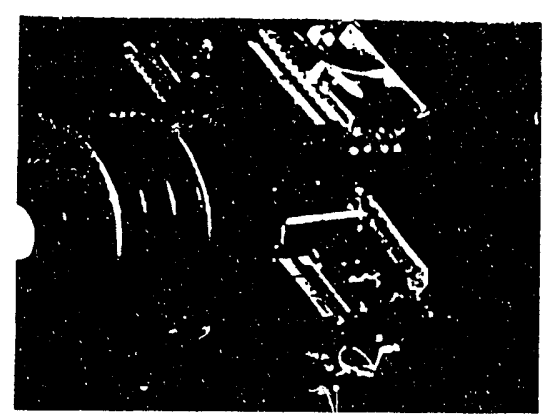

Figure 4. Photograph of the $6 \times 4$ machine showing the induction core and switch stacks.

There is no energy recovery system on this machine, so the reset capacitor voltage is controlled by an external power supply and regulated by zener diodes. Switch stack voltage and cell voltage are both measured using high-impedance probes, while the switch and reset currents are measured using eight, $50-\mathrm{m} \Omega$ current-viewing resistors (CVR).

A digitized record of a single switch stack voltage, four switch currents and four reset currents are all shown in Figure 5 (a) through (c).

(a)

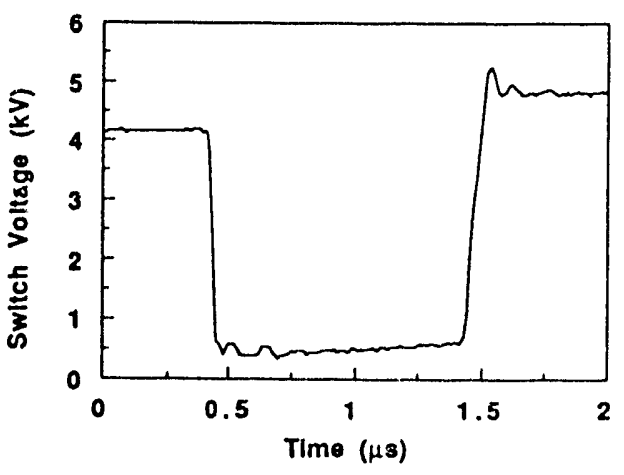

(b)

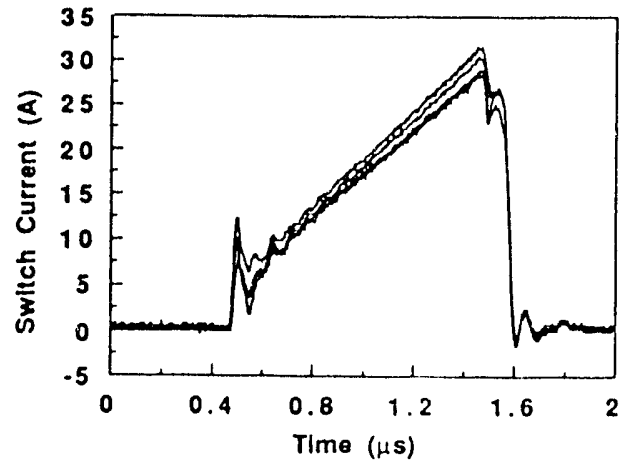

(c)

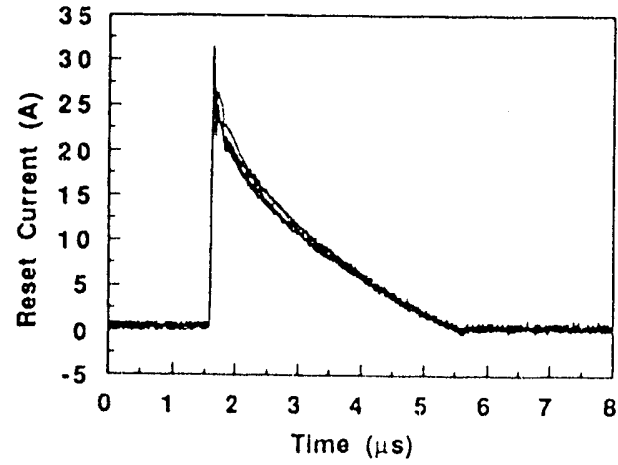

Figure 5. (a) One of four switch stack voltages. (b) Overlay of four switch branch currents. (c) Overlay of four reset branch currents. 
The superimposed current data indicate good current sharing between the various switch and reset branches due to precise switch timing and and similar on-state resistances. The measured cell voltage is shown in Figure 6 along with the total cell current, which is a computer summation of all the switch and reset currents from Figure 5. The small voltage spike at the start of the reset interval is due to the reset circuit inductance.

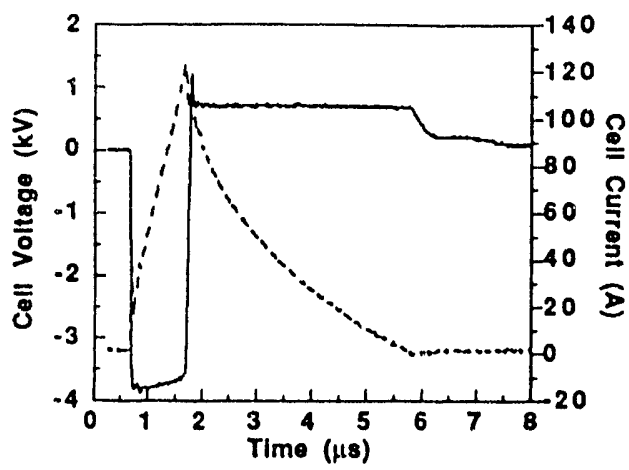

Figure 6. Cell voltage (solid line) and total cell current (dashed line).

An illustration of pulse width agility is shown in Figure 7(a) for two pulses with different widths but a constant reset voltage. Similarly, Figure 7(b) shows a two-pulse change in reset voltage for a constant pulse width.

(a)

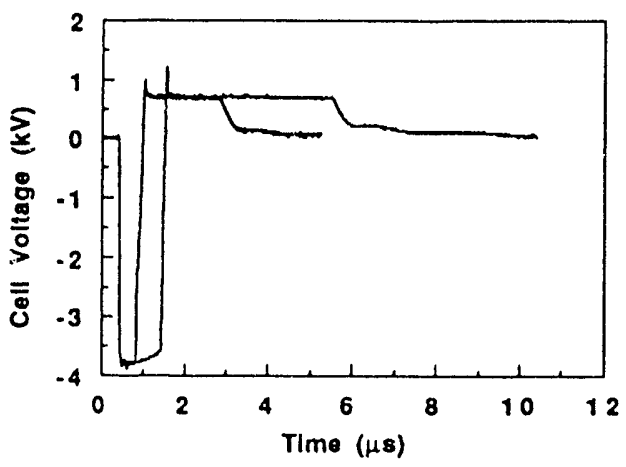

(b)

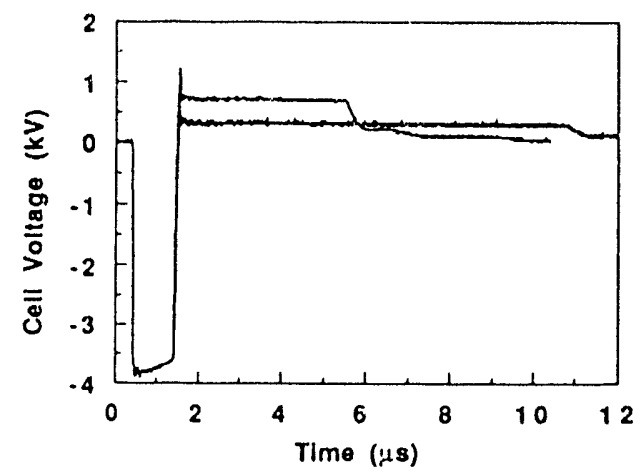

Figure 7. Comparison of reset intervals for two pulses: (a) A 400-ns pulse and a $1-\mu$ s pulse are compared for a constant reset voltage of $700 \mathrm{~V}$. (b) Two $1-\mu$ s pulses are compared with reset voltages of $700 \mathrm{~V}$ and $300 \mathrm{~V}$.

One should note that variations in pulse width or reset voltage are automatically matched by a shift in the reset interval. Consequently, the acceleration and reset pulses have equal voli-second products. Figure 8 shows the coll voltage during a five-pulse burst at a $100-\mathrm{kHz}$ prf. The energy for all five pulses is supplied by a single charge from the core-mounted capacitor banks.

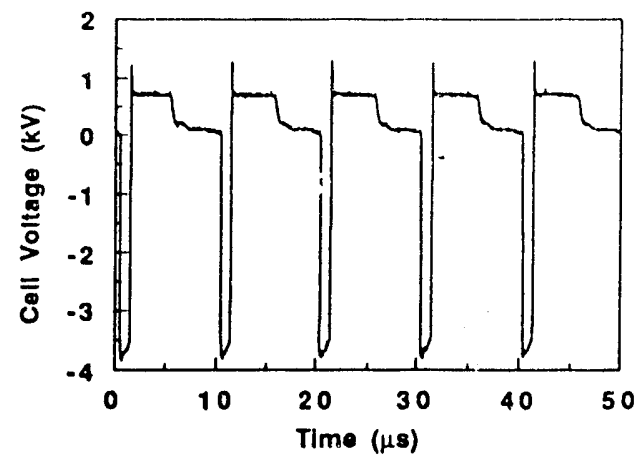

Figure 8. Cell voltage record for a five-pulse burst of $1-\mu$ s pulses with pulse separation of $10 \mu \mathrm{s}(100-\mathrm{kHz}$ prf $)$.

A safe operating area for the machine is primarily determined by the FET array limitations for breakdown voltage and pulsed current. The array current limit can be reached by an excess of either pulse width or charge voltage. The array breakdown voltage may be exceeded by the sum of the charge voltage, reset voltage, and any pulse overshoot. The maximum prf is operationally limited by restricting the pulse wicith and reset interval combination to be less than the burst period.

\section{BSpice Modeling}

We selected PSpice to assist us with the $6 \times 4$ machine analysis and to assess the next generation of machine designs. We were especially interested in tracing the flux density behavior in the $6 \times 4$ machine core to determine if the reset circuit provided an open or closed flux cycle. The magnetic simulation parameters in PSpice were adjusted to match both small-core test data and an empirical equation that best fit available test data in the literature [10]. A single-pulse comparison of simulation and measured data is shown in Figure 9. A multipulse simulation of the core's B-H loop trajectory is shown in Figure 10

(a)

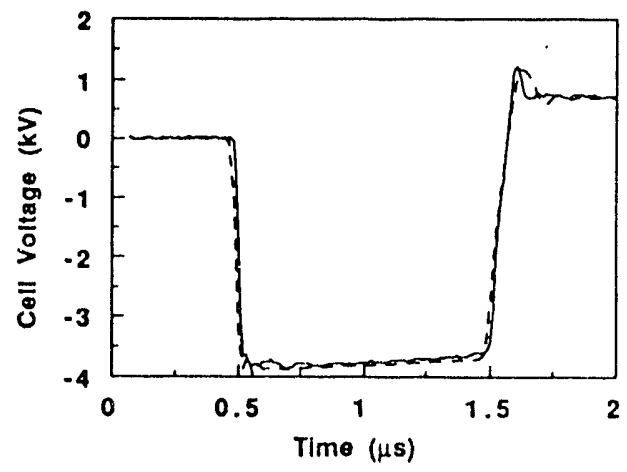

(b)

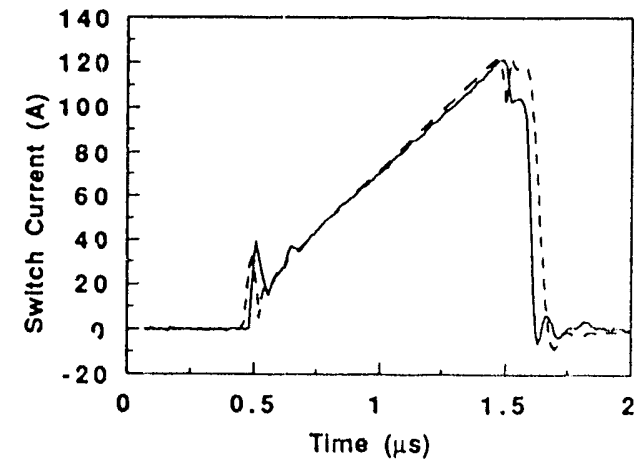

Figure 9. Single-pulse comparisons between measured data (solid line) and PSpice simulations (dashed line): (a) Cell voltage. (b) Switch current for all four branches. 


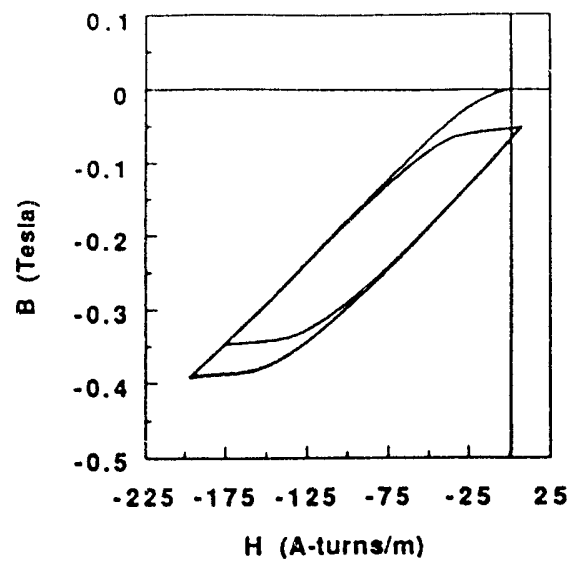

Figure 10. Plot of the core's magnetic flux density (B) vs magnetic field intensity $(H)$ for a four-pulse simulation.

The loop simulation starts at the B-H origin to illustrate that the network provides a stable reset condition after a few pulses. More information is available about our modeling effort from Ollis, et al., in these proceedings [11].

\section{Next Generation Machine}

Plans for our next induction cell include increases in cell voltage and power-handling capacity with decreases in machine size and cost per kilowatt. The recirculator specifications for voltage and burst duration require our new induction cell to exceed a $5-\mathrm{kV}$ cell voltage and to be powered from a large external capacitor bank. The new machine will also be smaller than the $6 \times 4$ machine by using one third less core material and surface-mount electronics for the gate drive circuits. We plan to increase the new machine's peak and average power capacities while lowering the system cost per kilowatt by using 32 power converters and optical links to serve 64 gate drive circuits. Similarly, each gate drive circuit commands two power FETs in parallel to yield a total of $128 \mathrm{FETs}$. The general circuit architecture remains the same as the $6 \times 4$ machine, but this new device places eight parallel modules around a smaller core with eight series switching elements per module. We call this array configuration our 8 x 8 machine and list its electrical specifications in Table 2 .

\section{Table 2}

Electrical Specifications

Total machine capacitance

Cell inductance

$4.8 \mu \mathrm{F}$ (four banks)

Peak cell current@1 $1 \mu \mathrm{s}, 5 \mathrm{kV} 208 \mathrm{~A}$

Maximum: stored energy charge voltage array voltage array current

Minimum:

pulse separation reset interval

\section{$86.4 \mathrm{~J}$}

$6 \mathrm{kV}$ (capacitor limit)

$8 \mathrm{kV}$ (FET stack limit)

$670 \mathrm{~A}$ (pulsed)

$$
6.67 \mu \mathrm{s}(150 \mathrm{kHz})
$$

$5 \mu \mathrm{s}$

\section{Summary and Conclusions}

We developed a compact cell and modulator combination that generates $4-\mathrm{kV}, 1-\mu \mathrm{s}$ pulses onto a Metglas induction core at pulse rates exceeding $100 \mathrm{kHz}$. The solid-state circuit architecture has an ability to power an all-inductive load, freely vary pulse width and prf. and provide for cell reset between pulses. PSpice models have also been developed and show a reasonable agreement with measured data. Construction is underway on a new device that will yield higher cell voltages and pulse rates.

We believe our FET-switched device is.a good example of smart power management applied to a pulse power problem [12]. In this context, a "smart" pulse power system can adapt to rapidly changing load conditions hecause the advanced switching technology can communicate with a computer-based control system. Smart power management is required for heavy-ion recirculators and we believe it also applies to other industrial applications where small size, reliability, efficiency and low cost are prime issues.

\section{References}

[1] Fusion Policy Advisory Committee, Final Report, September 1990, p. 6.

[2] "HIBALL-II, An Improved Heavy-Ion Beam Driven Fusion Reactor Study," KfK-3480, Kernforschungszentrum Karlsruhe; FPA-84-4, Fusion Power Associates;' UWFDM-625, University of Wisconsin (July 1985).

[3] "HIBLIC-I, Conceptual Design of a Heavy-Ion Fusion Reactor," IPPJ-663, Research Informaition Center, Institute for Plasma Physics, Nagoya University (Janliary 1985).

[4] D. J. Dudziak, Ed., "HIFSA: Heavy-Ion Fusion Systems Assessment Project Technical Analyses," LA-11141-MS, Vol. II, Los Alamos National Laboratory (December 1987).

[5] "Study of Recirculating Induction Accelerators as Drivers for Heavy Ion Fusion," Lawrence Livermore National Laboratory, UCRL-LR-108095 (September 1991).

[6] E. P. Lee, "Beam Dynamics and Longitudinal Instabilities in Heav'-Ion-Fusion Induction Linacs," Proceedings of the 1992 Linear Accelerator Conference, Ottawa, Ontario, Canada, August 24-28, 1992, p. 591.

[7] J. C. Bendien, H. Van Der Broeck, and G. Fregien, "Recovery Circuit for Snubber Energy in Power Electronic Applications with High Switching Frequencies," IEEE Trans. on Power Electronics, Vol. 3, No. 1, January, 1988.

[8] G. T. Santamaria and R. M. Ness, "High Power Switching Using Power FET Arrays," Proceedings of the 6th IEEE Pulsed Power Conference, Arlington, VA, June 29-July 1, 1987, p. 161.

[9] H. C. Kirbie, et al., "Evolution of High-Repetition-Rate Induction Accelerators Through Advancements in Switching," Proceedings of the 1992 Linear Accelerator Conference, Ottawa, Ontario, Canada, August 24-28, 1992, p. 595.

[10] R. Kuenning, et al., "Long Pulse Accelerator," Lawrence Livermore National Laboratory, Beam Research Memo; RM-8943 (October 1989).

[11] C. W. Ollis, et al., "Spice Modeling of a FET-Switched Induction Accelerator Cell," Proceedings of the 9th IEEE Pulsed Power Conference, Albuquerque, NM, June 21-23, 1993.

[12] B. J. Baliga, "An Overview of Smart Power Technology," IEEE Trans. on Electron Devices, Vol. 38, No. 7, July, 1991. 

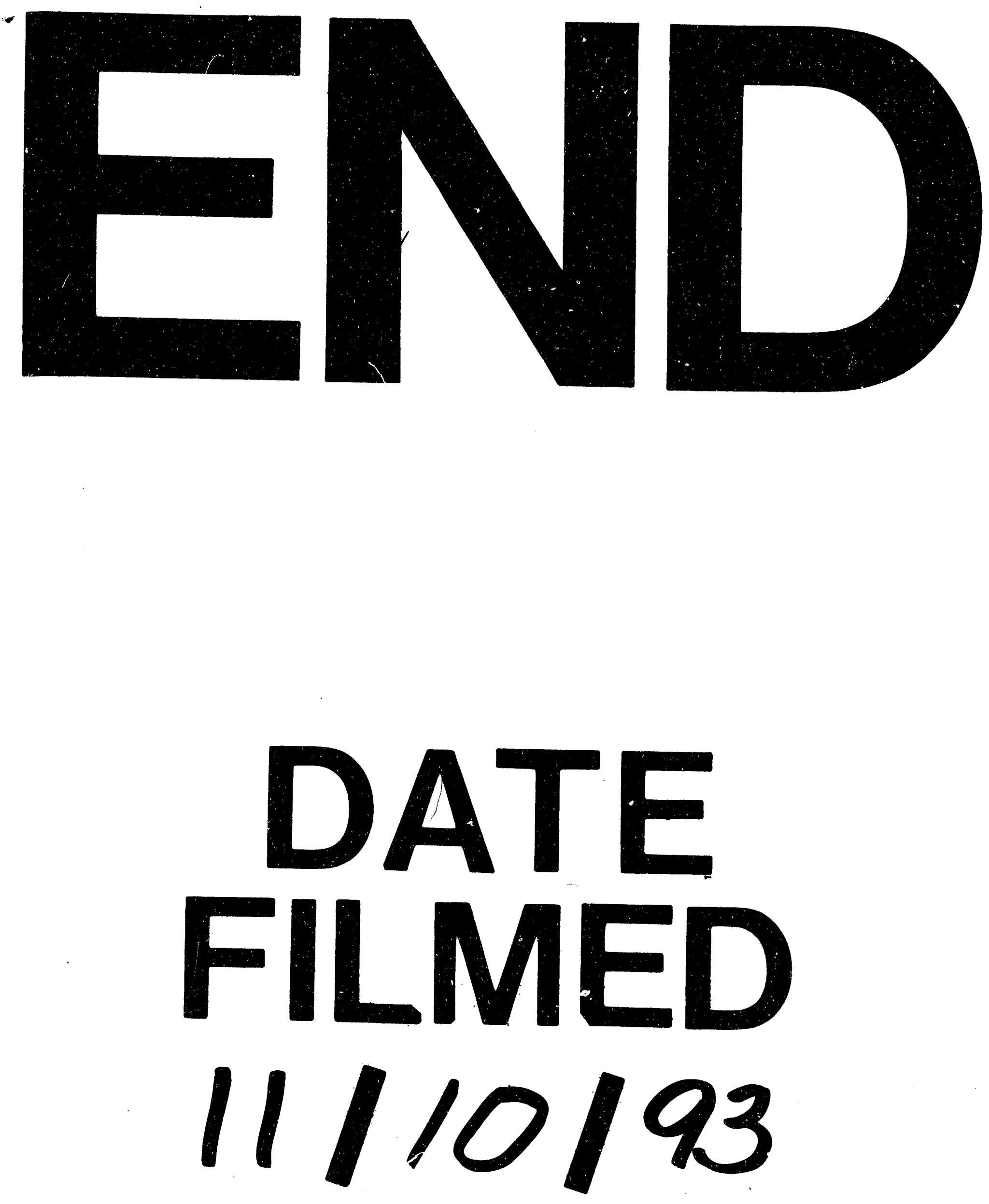
